\title{
Ciclo de mejora en el aula en docencia universitaria \\ en Odontología
}

\section{Classroom improvement cycle in university teaching in Dentistry}

DANiEL CABANILLAS BALSERA

ORCID: https://orcid.org/0000-0002-9978-6458

Universidad de Sevilla

Departamento de estomatología

dcabanillas@us.es

DOI: http://dx.doi.org/10.12795/9788447231003.007

Pp.: 154-171 


\section{Breve descripción del contexto}

La puesta en práctica del Ciclo de Mejora en el Aula (CIMA) que se describe en el presente capítulo se ha llevado a cabo en la asignatura denominada Clínica de Rehabilitación Protésica y Patología de la Oclusión. Dicha asignatura se imparte en el Máster Universitario en Odontología Restauradora, Estética y Funcional, que presenta un único curso, con un total de 20 alumnos. Este alumnado es ya Licenciado o Graduado en Odontología, y se encuentra cursando un máster profesionalizante.

Esta asignatura presenta 12 créditos ECTS, en su totalidad de actividad de prácticas clínicas odontológicas. En ellas se lleva a cabo la asistencia a pacientes con problemas de rehabilitación oral. Los contenidos a desarrollar en la asignatura es la realización de diagnóstico, pronóstico y tratamiento rehabilitador mediante protésis removible, fija y/o sobre implantes del paciente parcial y/o totalmente desdentado, así como de pacientes con alteraciones oclusales y/o desórdenes témporo-mandibulares, en función de la patología presente en el paciente a tratar.

Finalmente cabe destacar que, debido al carácter práctico, la actividad odontológica se realiza en un área de gabinetes o boxes clínicos.

Ciclos de Mejora en el Aula (2020). Experiencias de Innovación Docente de la US Esta obra se distribuye con la licencia Creative Commons 


\section{Diseño previo del ciclo de mejora}

El diseño del CIMA se plantea mediante una estructuración previa de los contenidos en un mapa y una propuesta de modelo metodológico y de actividades secuenciadas para alcanzarlo, estructurando de esta manera los objetivos del aprendizaje. Además, la elaboración de un cuestionario inicial-final permite valorar la evolución del aprendizaje de los alumnos a lo largo de este proceso.

\section{Mapa de contenidos y problemas claves que describa los aprendizajes deseables y los núcleos de trabajo en el aula.}

El primer paso en el diseño del ciclo de mejora implica analizar con detenimiento los contenidos que se van a impartir durante las sesiones en las que llevaremos a cabo este. En la figura 1 se presenta el mapa de contenidos a abordar durante la aplicación del CIMA (Ver figura 1).

Como podemos observar en la figura, debido al carácter eminentemente práctico de esta asignatura, la mayoría de los contenidos son procedimentales, tanto intelectuales como psicomotrices. También es importante destacar los contenidos actitudinales, puesto que los alumnos deben desarrollar y aprender actitudes como la empatía, la profesionalidad, o la confianza, a la hora del trato con los pacientes.

Ciclos de Mejora en el Aula (2020). Experiencias de Innovación Docente de la US Esta obra se distribuye con la licencia Creative Commons 


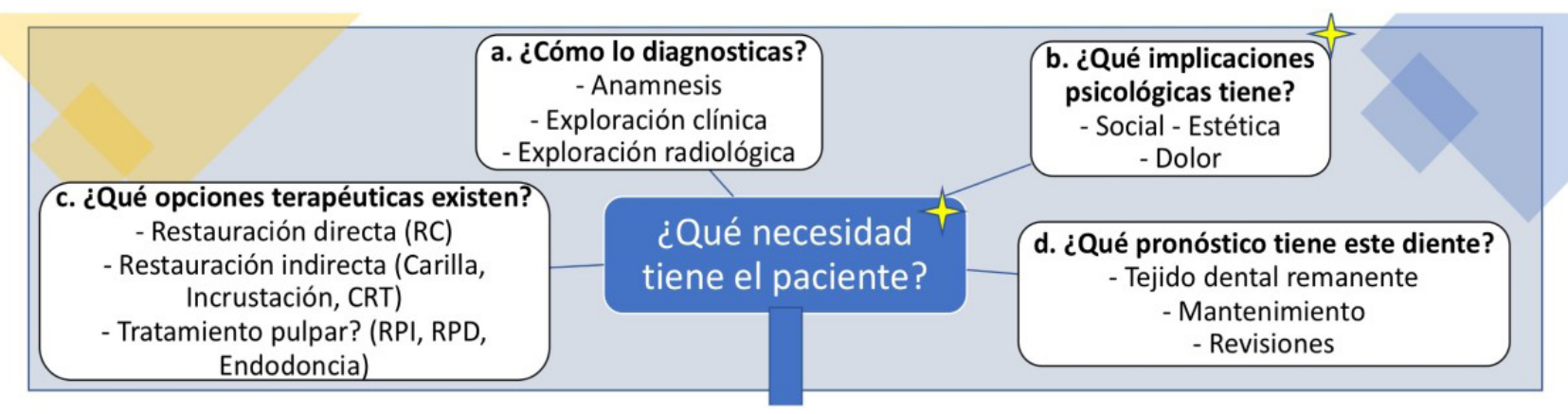

\section{¿Cómo abordarías una fractura coronaria?}

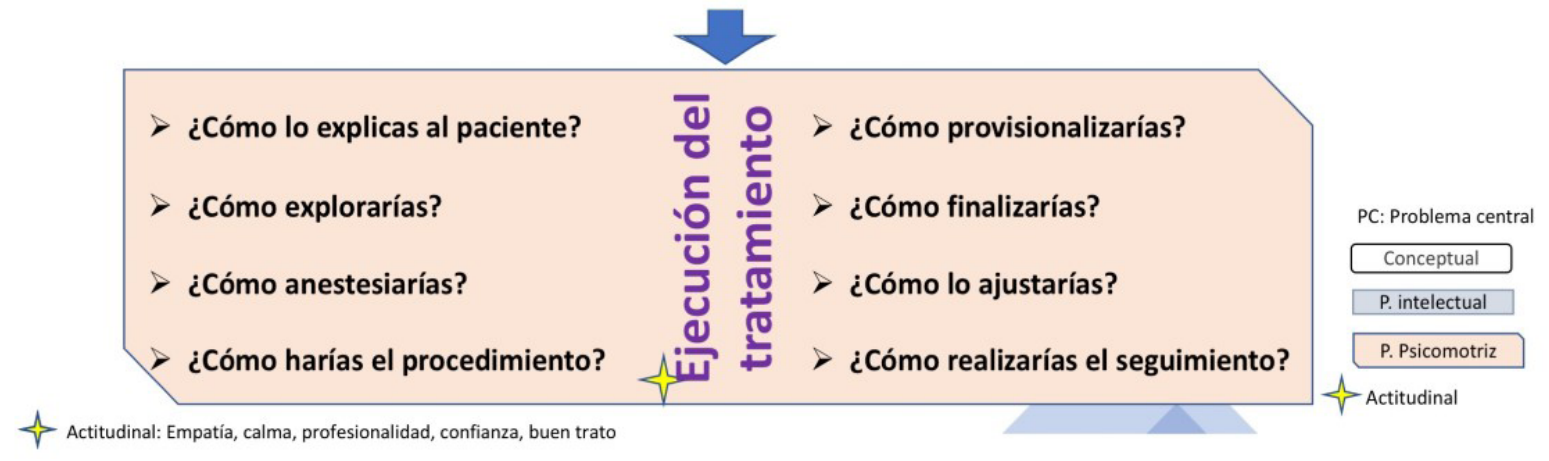

Figura 1. Mapa de contenidos

Ciclos de Mejora en el Aula (2020). Experiencias de Innovación Docente de la US (c) E) Esta obra se distribuye con la licencia Creative Commons 
Modelo metodológico posible y secuencias de actividades programadas, partiendo de los problemas seleccionados

La segunda cuestión a plantear en el diseño del CIMA es el modelo metodológico que vamos a emplear en su desarrollo. Así, el modelo metodológico propuesto en este caso puede representarse mediante el siguiente esquema (Figura 2):

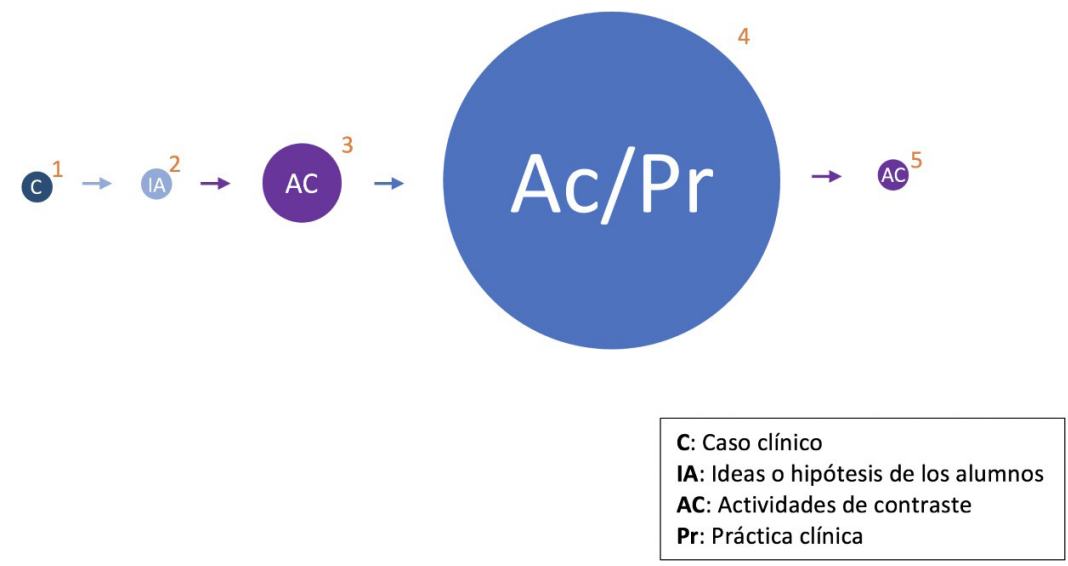

Figura 2. Modelo metodológico posible

Este modelo metodológico consta de 5 fases:

1. Presentación de un caso clínico de Fractura Coronaria a los alumnos

2. Los alumnos plantearán y madurarán sus hipótesis acerca de las cuestiones planteadas.

3. Los alumnos expondrán sus hipótesis, y habrá un debate entre los propios alumnos y entre estos y el profesor. Dentro de esta fase se aportará información adicional (empleando otros casos clínicos) en los que se cuestionen las ideas elaboradas por los alumnos.

4. Se llevará a cabo el procedimiento planteado de manera práctica, aplicado directamente sobre

Ciclos de Mejora en el Aula (2020). Experiencias de Innovación Docente de la US Esta obra se distribuye con la licencia Creative Commons 
los pacientes. Durante su desarrollo, habrá una cierta interacción por mi parte, en la cual, además de corregir o modificar posibles deficiencias de los procedimientos psicomotrices, se plantearán ideas de contraste sobre el tratamiento.

5. Se hará una puesta en común del desarrollo de la práctica clínica, debatiendo la resolución de las mimas, y contrastando con otras posibles soluciones.

Debemos destacar en este modelo la importancia de las actividades de contraste, empleadas con la intención de que, mediante el aporte de determinada información por nuestra parte, el alumno cuestione, mejore y reconstruya sus propias ideas (Bain, 2007).

Una vez hemos llevado a cabo la sintesis de las diferentes fases que vamos a seguir para generar un aprendizaje de calidad, pasamos a concretar las actividades. De esta manera, la secuencia de actividades propuestas es la siguiente:

Ciclos de Mejora en el Aula (2020). Experiencias de Innovación Docente de la US Esta obra se distribuye con la licencia Creative Commons 
DANIEL CABANILLAS BALSERA

\section{Tabla 1. Secuencia de actividades del ciclo de mejora}

\begin{tabular}{|c|c|c|c|}
\hline \multicolumn{4}{|c|}{ Un paciente acude a consulta presentando una fractura coronaria. ¿Cómo actuamos? } \\
\hline $\begin{array}{l}\text { № de actividad y } \\
\text { tiempo previsto }\end{array}$ & $\begin{array}{l}\text { Nombre } \\
\text { reconocible }\end{array}$ & Descripción de la actividad ¿en qué consiste? & Contenidos abordados \\
\hline $\begin{array}{c}1 . \\
15 \text { minutos. } \\
\text { Fase } 1 \text { y } 2 \\
\text { del modelo } \\
\text { metodológico }\end{array}$ & $\begin{array}{l}\text { Trabajo en } \\
\text { grupo sobre } \\
\text { caso clínico }\end{array}$ & $\begin{array}{l}\text { Esta actividad la realizarán los } 10 \text { alumnos del grupo por parejas (como ya tienen } \\
\text { asignadas para el resto de su actividad en el máster), analizando un caso clínico } \\
\text { que les proporcionaré proyectado (para una mejor calidad de las imágenes). } \\
\text { Se presentará un caso clínico de un paciente que presenta fractura coronaria } \\
\text { (Fase } 1 \text { del modelo metodológico). } \\
\text { Deberán analizarlo de manera habitual para los casos clínicos, teniendo en } \\
\text { cuenta la necesidad del paciente, y en los que se responden las siguientes } \\
\text { cuestiones (Fase } 2 \text { del modelo metodológico): } \\
\text { • ¿Cómo podemos saber qué cantidad de diente se ha visto afectado? ¿Y a } \\
\text { cuántos dientes ha afectado? Explícalo con detalle. } \\
\text { - La pareja del paciente está asustada y, el paciente se encuentra nervioso } \\
\text { ¿cómo actuarías con ellos? } \\
\text { ¿Debemos centrarnos solo en el diente o también profundizar sobre si la frac- } \\
\text { tura se acompaña de alguna otra patología como consecuencia del golpe?, ¿es } \\
\text { relevante? ¿Cómo averiguarlo? } \\
\text { Teniendo en cuenta la valoración que has hecho, ¿qué tratamientos propon- } \\
\text { drías? Explica con detalle tus propuestas de tratamientos. } \\
\text { Durante la cita observas que el traumatismo ha llevado a la fractura de todo } \\
\text { el frente anterior del paciente, sin afectar a la pulpa de los mismos. Describe } \\
\text { el tratamiento más adecuado en este caso. } \\
\text { El paciente te pregunta cuánto le va a durar el tratamiento que le planteas } \\
\text { ¿Qué le dirías? } \\
\text { El paciente tiene un viaje planeado el fin de semana, ¿harías o le recomenda- } \\
\text { rías algo hasta que puedas atenderlo? }\end{array}$ & $\begin{array}{l}\text { Diagnóstico: } \\
\text { · } \quad \text { Anamnesis } \\
\text { · } \quad \text { Exploración clínica } \\
\text { · } \quad \text { Exploración radiológica } \\
\text { Implicaciones psicológicas: } \\
\text { - } \quad \text { Sociales } \\
\text { - } \quad \text { Estéticas } \\
\text { - } \quad \text { Dolor } \\
\text { Opciones terapéuticas: } \\
\text { - } \quad \text { Restauración directa (RC) } \\
\text { - } \quad \text { Restauración indirecta (Carilla, } \\
\text { Incrustación, CRT) } \\
\text { - } \quad \text { Necesidad de algún tratamiento } \\
\quad \text { pulpar (RPI, RPD, tratamiento de } \\
\quad \text { conductos...) } \\
\text { Pronóstico del tratamiento y del } \\
\text { diente fracturado: } \\
\text { · } \quad \text { Tejido dental remanente } \\
\text { - Mantenimiento } \\
\text { - } \quad \text { Revisiones }\end{array}$ \\
\hline
\end{tabular}

Ciclos de Mejora en el Aula (2020). Experiencias de Innovación Docente de la US (C) Esta obra se distribuye con la licencia Creative Commons 


\begin{tabular}{|c|c|c|}
\hline $\begin{array}{c}2 . \\
15 \text { minutos. } \\
\text { Fase } 3 \text { del modelo } \\
\text { metodológico }\end{array}$ & $\begin{array}{l}\text { Actividades de } \\
\text { contraste sobre } \\
\text { caso clínico }\end{array}$ & $\begin{array}{l}\text { A los } 15 \text { minutos de haber comenzado esta actividad, les expondré algunas } \\
\text { imágenes de otros casos clínicos de fracturas, pero en los que existan diferencias } \\
\text { notables en el diagnóstico y, por tanto, en las posibilidades terapéuticas. De } \\
\text { esta manera, pretendo que reflexionen sobre la importancia de un correcto } \\
\text { diagnóstico, que determinará las posibilidades terapéuticas de dicho diente. } \\
\text { En este tiempo, además de poder consultarme acerca de cualquier cuestión que } \\
\text { les pueda ir surgiendo, también iré indagando sobre la evolución de las ideas de } \\
\text { las parejas. } \\
\text { Las cuestiones planteadas además deberán estar razonadas mediante literatura } \\
\text { científica que la avale. }\end{array}$ \\
\hline $\begin{array}{c}3 . \\
65 \text { minutos. } \\
\text { Fase } 3 \text { del modelo } \\
\text { metodológico }\end{array}$ & $\begin{array}{l}\text { Puesta en } \\
\text { común }\end{array}$ & $\begin{array}{l}\text { En esta actividad pondrán en común las conclusiones y el trabajo abordado en } \\
\text { cada pareja. Para ello contarán con } 10 \text { minutos cada pareja, de los cuales } 7 \text { minutos } \\
\text { será de exposición de las cuestiones planteadas, con los motivos razonados de } \\
\text { los mismos, y los } 3 \text { restantes para posibles cuestiones o comentarios particulares } \\
\text { a la exposición. } \\
\text { Una vez terminadas las exposiciones, en los } 15 \text { minutos restantes se llevará a } \\
\text { cabo un debate general de conclusiones abordando tanto las ideas comunes } \\
\text { como las diferentes de los trabajos por parejas, en el que participaré haciendo } \\
\text { reflexiones sobre los diferentes aspectos surgidos. } \\
\text { En esta fase final, además, se volverán a mostrar los casos clínicos adicionales } \\
\text { que se muestran en la actividad no } 1 \text {, de tal manera que se identifiquen o } \\
\text { analicen las diferencias o particularidades de estos casos, comparados con el } \\
\text { caso clínico central. }\end{array}$ \\
\hline
\end{tabular}

Ciclos de Mejora en el Aula (2020). Experiencias de Innovación Docente de la US 


\begin{tabular}{|c|c|c|c|}
\hline $\begin{array}{l}4 . \\
6 \text { horas. } \\
\text { Fase } 4 \text { del modelo } \\
\text { metodológico }\end{array}$ & Práctica clínica & $\begin{array}{l}\text { Se llevará a cabo la atención a los pacientes. Lógicamente esta parte depende } \\
\text { de la demanda de los pacientes que acudan a cita los días programados. } \\
\text { No obstante, al haber elegido una patología frecuente en la práctica diaria, } \\
\text { previsiblemente las } 5 \text { parejas de alumnos podrán tener un paciente en el que } \\
\text { desarrollar el procedimiento de los contenidos propuestos. } \\
\text { Esta actividad deberá fragmentarse por necesidades horarias, en las que el } \\
\text { primer día se llevará a cabo durante } 2 \text { horas y } 25 \text { minutos (el tiempo restante } \\
\text { con las actividades anteriores, hasta completar las } 4 \text { horas de su horario), y la } \\
\text { semana siguiente durante } 3 \text { horas y } 35 \text { minutos. Sin embargo, será una única } \\
\text { actividad, fragmentada, con una continuación del mismo tratamiento y en el } \\
\text { mismo paciente. } \\
\text { En esta actividad se realiza la atención a los pacientes de manera habitual, } \\
\text { atendiéndolos por parejas, y en el que deban ejecutar los procedimientos } \\
\text { necesarios para el diagnóstico, explicación al paciente, exploración clínica } \\
\text { y radiológica, anestesia, tratamiento necesario, provisionalización, ajuste y } \\
\text { finalización, e indicaciones para el mantenimiento y seguimiento. } \\
\text { En este tiempo, como es habitual, los alumnos podrán consultarme cualquier } \\
\text { duda que pueda surgirles y, además, iré supervisando los diferentes pasos a lo } \\
\text { largo del procedimiento. }\end{array}$ & $\begin{array}{ll}\text { - } & \text { Explicación al paciente } \\
\text { - } & \text { Exploración clínica y radiológica } \\
\text { - } & \text { Ejecución de técnica anestésica } \\
\text { - } & \text { Ejecución del procedimiento } \\
& \text { clínico } \\
\text {. } & \text { Elaboración y colocación de } \\
& \text { provisional } \\
\text { - } & \text { Ajuste y finalización } \\
\text { - Indicaciones de mantenimiento y } \\
\quad \text { seguimiento al paciente }\end{array}$ \\
\hline $\begin{array}{l}5 . \\
25 \text { minutos. } \\
\text { Fase } 5 \text { del modelo } \\
\text { metodológico }\end{array}$ & $\begin{array}{l}\text { Puesta en } \\
\text { común }\end{array}$ & $\begin{array}{l}\text { En esta actividad pondrán en común las complicaciones y su abordaje que } \\
\text { hayan podido surgir a lo largo del procedimiento clínico en cada pareja. Para } \\
\text { ello, cada pareja contará con } 5 \text { minutos, de los cuales } 4 \text { minutos serán de } \\
\text { explicación de lo realizado, argumentando la resolución de complicaciones, y } 1 \\
\text { minuto para posibles cuestiones o comentarios a lo expuesto. }\end{array}$ & $\begin{array}{l}\text { Reflexiones sobre la ejecución del } \\
\text { procedimiento }\end{array}$ \\
\hline
\end{tabular}

Con este diseño de modelo metodológico y esta secuenciación de actividades se pretenden conseguir el objetivo de este ciclo de mejora: centrar la enseñanza en el alumno, de manera que generemos los condicionantes ideales para aprovechar al máximo su proceso de aprendizaje (Finkel, 2008).

Ciclos de Mejora en el Aula (2020). Experiencias de Innovación Docente de la US cc (i) $\odot$ Esta obra se distribuye con la licencia Creative Commons 

relación con los problemas y contenidos claves

Una vez hemos llevado a cabo el diseño del mapa de contenidos, del modelo metodológico y de la secuencia de actividades, es necesario incluir en el diseño del CIMA un cuestionario inicial-final que nos permita valorar la evolución del aprendizaje de los estudiantes. Por tanto, se elabora un cuestionario que aborda los contenidos que se van a desarrollar durante la aplicación del CIMA, y que incorpora las siguientes preguntas:

\section{Ante un traumatismo dental, ¿Cómo puedes actuar?}

Esto no es un examen. Estamos realizando un estudio sobre el aprendizaje de los alumnos en el Máster Oficial que estás cursando. Nos interesa mucho conocer cómo te enfrentarías ante la supuesta situación clínica que se plantea y que conocimientos echas en falta para esa situación.

Responde a las siguientes preguntas sin consultar absolutamente nada, con lo que sabes. Recuerda: ¡Esto no es un examen! y para tu tranquilidad, responde de forma anónima, utilizando un nombre inventado o pseudónimo.

Pseudónimo:

Imagínate que estás un día cualquiera en la clínica en la que trabajas y acude de urgencia un adulto, y te cuenta que jugando al fútbol se ha caído y se ha roto algo en los dientes:

1. ¿Cómo podemos saber qué cantidad de diente se ha visto afectado? ¿Y a cuántos dientes ha afectado? Explícalo con detalle.

2. La pareja del paciente está asustada y, el paciente se encuentra nervioso ¿cómo actuarías con ellos?

3. ¿Debemos centrarnos solo en el diente o también profundizar sobre si la fractura se acompaña de alguna otra patología como consecuencia del golpe?, ¿es relevante? ¿Cómo averiguarlo?

Ciclos de Mejora en el Aula (2020). Experiencias de Innovación Docente de la US Esta obra se distribuye con la licencia Creative Commons 
4. Teniendo en cuenta la valoración que has hecho, ¿qué tratamientos propondrías? Explica con detalle tus propuestas de tratamientos.

5. Durante la cita observas que el traumatismo ha llevado a la fractura de todo el frente anterior del paciente, sin afectar a la pulpa de los dientes implicados. Describe el tratamiento más adecuado en este caso.

6. El paciente te pregunta cuánto le va a durar el tratamiento que le planteas ¿Qué le dirías?

7. El paciente tiene un viaje planeado el fin de semana, ¿harías o le recomendarías algo hasta que puedas atenderlo?

\section{Aplicación del CIMA}

Una vez hemos completado el diseño del CIMA, pasamos a llevarlo a la práctica y aplicarlo en nuestra docencia. Durante la aplicación de este CIMA es preciso elaborar un diario de sesiones, analizando el desarrollo de éstas y recogiendo los posibles cambios que se incorporan.

\section{Relato resumido de las sesiones}

Como estaba diseñado previamente, el CIMA se aplica en 2 sesiones de 4 horas cada una. Sin embargo, por falta de tiempo, tengo que extender la última actividad a una tercera sesión (25 minutos más de lo previsto). Debido a la existencia de diferentes actividades en una misma sesión, haremos el relato del CIMA por actividades. En la primera sesión se realiza la explicación de lo que se va a realizar y se entrega la hoja de instrucciones a cada uno de los alumnos.

Actividad 1: Tras presentarles el caso clínico y puesto que existe un tiempo relativamente breve para la resolución de las preguntas planteadas, los alumnos rápidamente se

Ciclos de Mejora en el Aula (2020). Experiencias de Innovación Docente de la US Esta obra se distribuye con la licencia Creative Commons 
ponen a debatirlas por parejas y a elaborar sus respuestas. Me sorprende la gran cantidad de cuestiones que les surgen a los alumnos acerca de condicionantes que creen necesarias para resolver las cuestiones. Sin embargo, decido esperar a la segunda actividad para empezar a plantear las actividades de contraste.

Actividad 2: Tras mi intervención planteando otros casos clínicos con diferencias notables respecto del problema principal, los alumnos comienzan a centrarse y madurar sus ideas. Ellos mismos empiezan a darse cuenta de que parte de sus dudas anteriores realmente estaban reflejadas en el caso expuesto, de manera que no les falta información, sino que no habían sabido analizarla. También en la búsqueda de bibliografía necesaria, vuelven a surgir nuevas dudas.

Una modificación o detalle que no había tenido en cuenta es mantener durante toda esta actividad (excepto durante la muestra de los casos propios de esta actividad) el caso clínico problema expuesto para que puedan continuar analizándolo según vayan surgiendo ideas.

Actividad 3: Una vez que los alumnos plantean sus exposiciones, genero un debate que resulta bastante interesante entre ellos por las diferentes opciones de tratamiento que se plantean. Aquí se pone de manifiesto, además de los conocimientos que han adquirido, que existen diferentes opciones de tratamientos para un mismo diagnóstico. Esta idea es algo que no había previsto plantearles, pero que es gran conocida entre el profesorado en odontología, por lo que aprovecho para ponerlo en evidencia.

Actividad 4: La práctica clínica supone una parte muy importante del tiempo de todo el CIMA. Los alumnos conocen (en cierta medida) los procedimientos intelectuales. Sin embargo, requieren una gran supervisión en los p. psicomotrices. Existe un gran avance en el aprendizaje de estos procedimientos durante el desarrollo del CIMA. No obstante, son procedimientos relativamente avanzados, que también irán desarrollando a lo largo del resto del curso. Se produce un retraso bastante considerable en algunos alumnos que obliga a retrasar la última actividad. 
Actividad 5: Debido a los retrasos en la actividad anterior, esta actividad tiene que ser pospuesta y decido aplicarla en el comienzo de una siguiente sesión (aunque estuviera fuera de hora del CIMA). Resulta muy fructífera para los alumnos, puesto que pueden corroborar cómo un mismo tratamiento presenta diferentes resoluciones según particularidades de cada paciente.

\section{Evaluación del aprendizaje de los estudiantes}

Una vez terminada la aplicación del CIMA, además de analizar por sesiones lo ocurrido, es preciso pasar a los alumnos el cuestionario final, de manera que, comparando sus respuestas con las respondidas inicialmente, podamos valorar el aprendizaje que ha tenido lugar. Mediante la organización y análisis de las respuestas de los estudiantes, y su agrupación según modelos o niveles de conocimiento, podemos elaborar escaleras de aprendizaje (Porlán, 2017).

En las figuras 3 y 4 , se muestran las escaleras de aprendizaje correspondiente a las preguntas 5 y 6 del cuestionario. En estas escaleras podemos observar los distintos niveles de aprendizaje de los alumnos, con el número en porcentajes de respuestas por nivel que han dado tanto en el cuestionario inicial como final. Así mismo, vemos reflejado el obstáculo existente entre cada nivel y el superior, que el alumno debe superar para alcanzar el estrato superior (Ver figuras 3 y 4).

Analizando las figuras de ambas escaleras, observamos un claro desplazamiento de las respuestas de los alumnos, estando representado en el cuestionario inicial unos mayores porcentajes entre los niveles inferiores, y siendo la evolución tras la aplicación del CIMA hacia unos porcentajes superiores en los niveles más altos, incluso conllevando a la aparición de un nuevo nivel de conocimiento superior que no estaba reflejado en las respuestas del cuestionario inicial.

Ciclos de Mejora en el Aula (2020). Experiencias de Innovación Docente de la US Esta obra se distribuye con la licencia Creative Commons 


\section{Evaluación del CIMA}

Una vez analizado el desarrollo del CIMA, pasamos a evaluar el propio CIMA. De esta forma, podemos determinar aquello que ha funcionado correctamente $\mathrm{y}$, por tanto, sería conveniente mantener en nuestra docencia. Sin embargo, de este análisis o evaluación pueden surgir cambios o mejoras a introducir en un futuro.

\section{Cuestiones para mantener y cambios a introducir para un futuro Ciclo de Mejora más amplio}

La evaluación del CIMA, en general, nos reporta que las sensaciones de los alumnos han sido muy positivas. Supone para ellos un mayor esfuerzo que empleando un método tradicional, pero es bien recibido, pues mejora la confianza en sí mismos para abordar al paciente. Sin embargo, en la actividad clínica en la cual abordan los procedimientos psicomotrices sigue existiendo un nivel global de aprendizaje inferior, puesto que muchos de ellos se están enfrentando a estos procedimientos por primera vez.

El diseño de las actividades para abordar los conceptos y procedimientos intelectuales los mantendría de manera similar para un futuro CIMA. No obstante, para un mayor aprovechamiento del tiempo existente, disminuiría el número de grupos formados, aumentando de 2 a 4 los alumnos por grupo, para las actividades de casos clínicos y actividades de contraste.

Por otro lado, teniendo en cuenta las deficiencias detectadas en los procedimientos psicomotrices, para un futuro CIMA plantearía un diseño que incorporara una actividad preclínica de tipo de taller, sobre fantomas o modelos, en el que poder realizar estos procedimientos previamente a la aplicación directa sobre los pacientes.

Ciclos de Mejora en el Aula (2020). Experiencias de Innovación Docente de la US Esta obra se distribuye con la licencia Creative Commons 


\section{Aspectos de la experiencia que se pretenden incorporar a toda la práctica docente habitual}

Como aspecto de la experiencia a incorporar en la docencia habitual puedo destacar la dinamización de las clases: generar enigmas, cuestiones que el alumno se plantee y deba resolver para que, de esta manera, se implique aún más en el proceso de aprendizaje. Esto además genera que los alumnos se interesen y sientan atraídos en mayor medida por los contenidos a abordar, traduciéndose en un mejor aprendizaje.

PREGUNTA 5. Durante la cita observas que el traumatismo ha llevado a la fractura de todo el frente anterior del paciente, sin afectar a la pulpa de los mismos. Describe el tratamiento más adecuado en este caso.

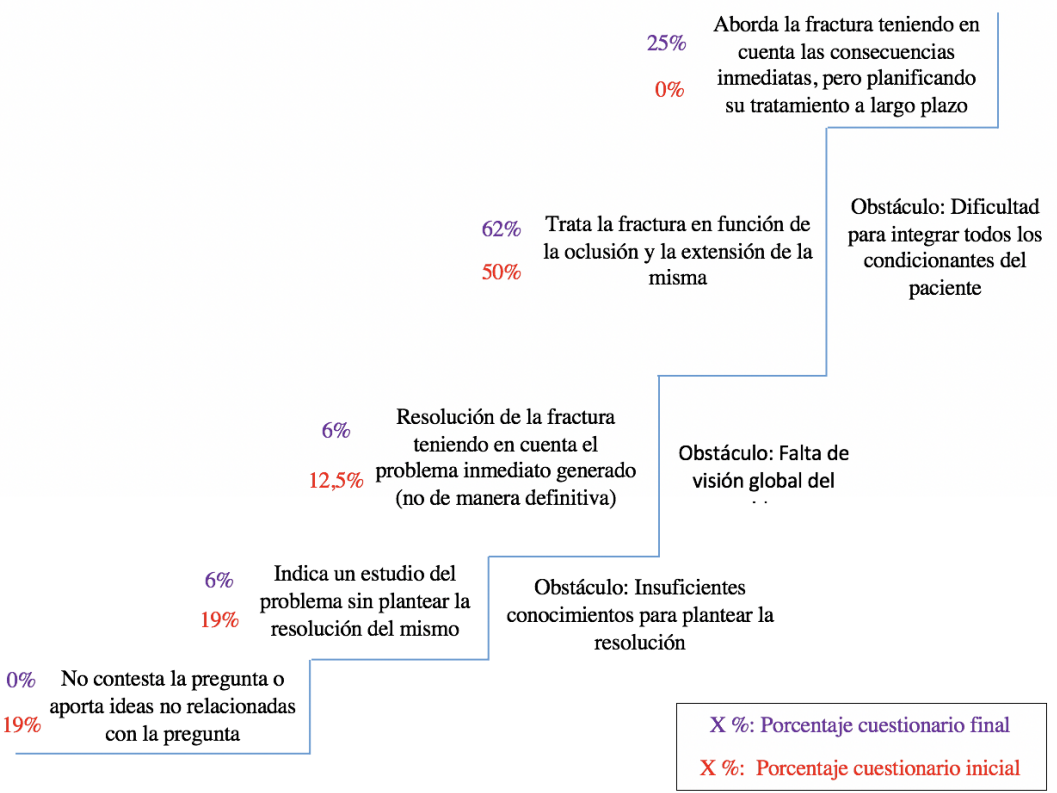

Figura 3. Escalera de aprendizaje de la pregunta 5

Ciclos de Mejora en el Aula (2020). Experiencias de Innovación Docente de la US Esta obra se distribuye con la licencia Creative Commons 


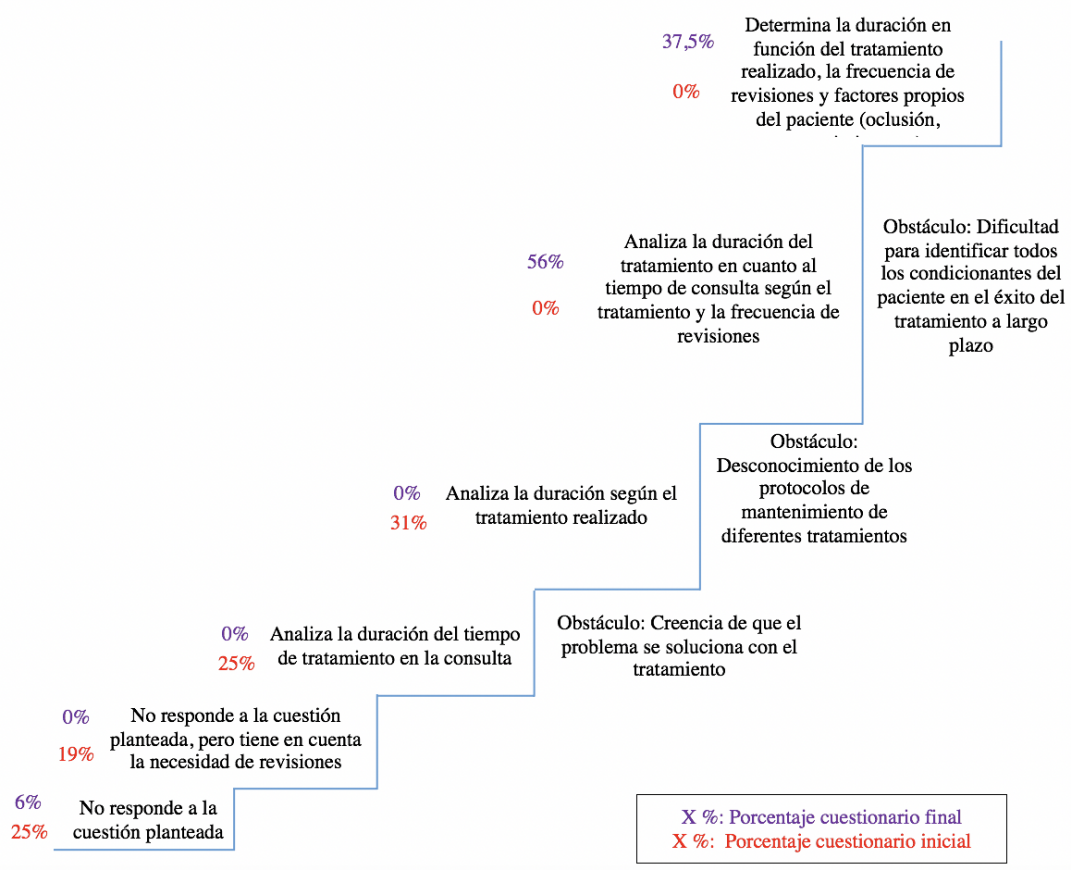

Figura 4. Escalera de aprendizaje de la pregunta 6

Principios Didácticos argumentados que han guiado la experiencia presente y que deben permanecer en el futuro

Finalmente, expongo los principios didácticos que considero más importantes en la actualidad, una vez finalizada la experiencia de innovación docente con el desarrollo de este CIMA:

- Tomar como partida los conocimientos de los alumnos para desarrollar los contenidos. El empleo de un cuestionario inicial nos permite analizar lo que los alumnos saben antes de impartir nuestra docencia. Si bien el mapa de contenidos es el primer paso en el diseño del CIMA, creo que sería interesante disponer de un análisis previo de cuestionario inicial que nos permita modificar o determinar los contenidos a abordar en la

Ciclos de Mejora en el Aula (2020). Experiencias de Innovación Docente de la US Esta obra se distribuye con la licencia Creative Commons 
docencia. En este sentido, tener en cuenta este punto de partida de los alumnos ayudaría a comprender y entender lo que enseñamos, y de esta forma, aprenderlo.

- Abordar una gran cantidad de contenidos no implica que los alumnos los asimilen y los aprendan. En muchas ocasiones intentamos abordar una gran cantidad de contenidos que están recogidos en el programa de la asignatura, de manera rápida, y que al final quedan en el olvido de los alumnos. Sin embargo, los contenidos deben diseñarse en función de las necesidades de los alumnos, teniendo en cuenta, además de los conocimientos previos, los contenidos esenciales que deben aprender. Por tanto, puede resultar interesante enseñar "menos cantidad" pero mejorando la calidad de lo aprendido.

- Utilización de aprendizaje basado en problemas y actividades de contraste como medio fundamental para el aprendizaje de los alumnos. El diseño de estas actividades fomenta la inquietud y curiosidad de los alumnos por los contenidos que se pretenden abordar, a la vez que generan un pensamiento crítico, procesado y maduración de sus propios argumentos. Por tanto, estas actividades permiten a los alumnos reconstruir y mejorar sus ideas propias y sus modelos mentales.

- Aportar la suficiente autonomía a los alumnos que les permita tomar decisiones y adquirir responsabilidades. Puesto que los alumnos de Odontología tienen que enfrentarse en su trabajo diario a diversos dilemas o problemáticas, además de la gestión propia de la clínica para el tratamiento del paciente, considero imprescindible para ellos desarrollar la autonomía, de forma que adquieran responsabilidades en cuanto a toma de decisiones, horarios, secuenciación de tratamientos, programación de citas... (lógicamente con una supervisión por parte del profesorado).

Ciclos de Mejora en el Aula (2020). Experiencias de Innovación Docente de la US Esta obra se distribuye con la licencia Creative Commons 
Palabras clave: Clínica de rehabilitación protésica y patología de la oclusión; Máster universitario en odontología restauradora, estética y funcional; docencia universitaria; experimentación docente universitaria; innovación docente.

Keywords: Prosthetic rehabilitation and occlusion pathology clinic; Master's degree in restorative, aesthetic and functional dentistry; university teaching; university teaching experimentation; teaching innovation.

\section{Referencias bibliográficas}

Bain, K. (2007). Lo que hacen los mejores profesores universitarios. Valencia: Publicaciones de la Universidad de Valencia.

Finkel, D. (2000). Dar clase con la boca cerrada. Valencia: Publicaciones de la Universidad de Valencia

Porlán R. (Coord.) (2017). Enseñanza Universitaria. Cómo mejorarla. Madrid: Morata

Ciclos de Mejora en el Aula (2020). Experiencias de Innovación Docente de la US Esta obra se distribuye con la licencia Creative Commons 